\title{
Innovative Evaporative Cooling System Toward Net Zero Energy Buildings
}

\author{
Andreu Moià-Pol ${ }^{a, 1}$ Victor Martínez-Moll ${ }^{\mathrm{a}}$, Susana Hormigos ${ }^{\mathrm{a}}$, Andrey Lyubchik $^{\mathrm{b}}$ \\ a Department of Industrial Engineering and Construction, UIB, Spain \\ ${ }^{\mathrm{b}}$ REQUIMTE, Universidade Nova de Lisboa, 2829-516, Caparica, Portugal
}

\begin{abstract}
The SSHARE project will develop innovative self-sufficient envelope for buildings aimed at net zero energy, thereby contributing to the European technology. Envelope is a combination of two breaking through technologies: HUNTERHumidity to Electricity Convertor and Advanced Radiant Panel for Buildings that will cool or heat the building, depending on the time of year, imitating perspiration of living beings and using only water as both thermal and electric energy supply. Successful realization of the project is assured by implementing a coordinated network of knowledge sharing in materials science, chemistry and mechanical engineering; by solidifying the state-of-the-art understanding in nanoelectronics and energy efficiency, and by applying bottom-up nanoengineering approaches via an international and inter-sector collaboration of highly qualified researchers from Portugal, Spain, Ukraine, Belarus, Tajikistan, Uzbekistan, Azerbaijan and the Joint Institute for Nuclear Research Russian Federation. Technological (panels fabrication) as well as fundamental (renewable energy) issues will be assessed by this multidisciplinary consortium. This paper explains the basis and principles for the development of a new generation of building materials and hence the creation of net zero building. Sharing the culture of research and innovation, the SSHARE project will allow applying recent advancements in nanotechnology science and mechanical engineering to address "'Plus Energy Houses"' EU 2050 concept.".
\end{abstract}

Keywords. Renewable Energy, Humidity to electricity, Evaporative cooling, Zero Energy Building

\section{Introduction}

There is a lot of research in using Thermal Energy Storage as a passive technology whose objective is to provide thermal comfort with minimal use of Heating Ventilation and Air Conditioning (HVAC) energy [1]. When high thermal-mass materials are used in buildings, passive sensible storage is the technology that allows the storage of a high quantity of energy, providing thermal stability inside the building.

Materials typically used in the construction are rammed earth, alveolar bricks, concrete, or stone. Standard walls, use sensible storage to achieve energy savings in buildings in winter, reducing thermal losses from the wall. For example, with Trombe walls the air between wall and glass could be heated and thus introduced into the room with a natural draught due to the chimney effect of the heated air an effect valid at summer and winter. Other systems can be used alongside to reduce the energy consumption, like geocooling

${ }^{1}$ Department of Industrial Engineering and Construction. University of Balearic Islands, Ctra. Valldemossa km. 7, 5, 07122 Balearic Islands (Spain), e-mail: andreu.moia@uib.es. 
or geoheating. The University of Balearic Islands has developed a radiant system to recover the latent heat for indoor applications [2]. The same system now is tested for outdoor use, aimed to use evaporative cooling of a permeable surface, imitating the effect of the perspiration of living beings, using only water as thermal energy supply.

Sprinkling water or irrigating on permeable surfaces can effectively reduce the convective sensible heat flux discharge and increase the latent heat flux. [3] In the majority of the Mediterranean countries historically the buildings are designed with a water storage due to the low annual precipitation and periods of drought, and many houses by law have a large rain water storage tank. Combining this storage with other technologies (solar, heat pump,..) through a proper system, could allow all the energy from solar radiation to be used for heat and cool the building. The heat can be dumped into a tank and use the water storage like a big buffer tank in the cooler days: this being more efficient than the geothermal systems. [4] The water in the basement could be between $5-20^{\circ} \mathrm{C}$ according to the place and the period. These temperatures are adequate to be used for refrigeration or heating of the building internally and externally. The new system of energy recovery using humidity, presents the possibility of generating electric energy through conversion of moisture adsorption energy on the surface of $\mathrm{ZrO}_{2}$ based on nanopowder systems into electrical charges. Investigated tablets were estimated to produce a maximum power density of about $10 \mathrm{nW} / \mathrm{cm}^{2}$ [5], developed in the HUNTER project that now is used in the SSHARE project [8]. This project is a collaboration of researchers from Portugal, Spain, Ukraine, Belarus, Tajikistan, Uzbekistan, Azerbaijan and the Joint Institute for Nuclear Research Russian Federation.

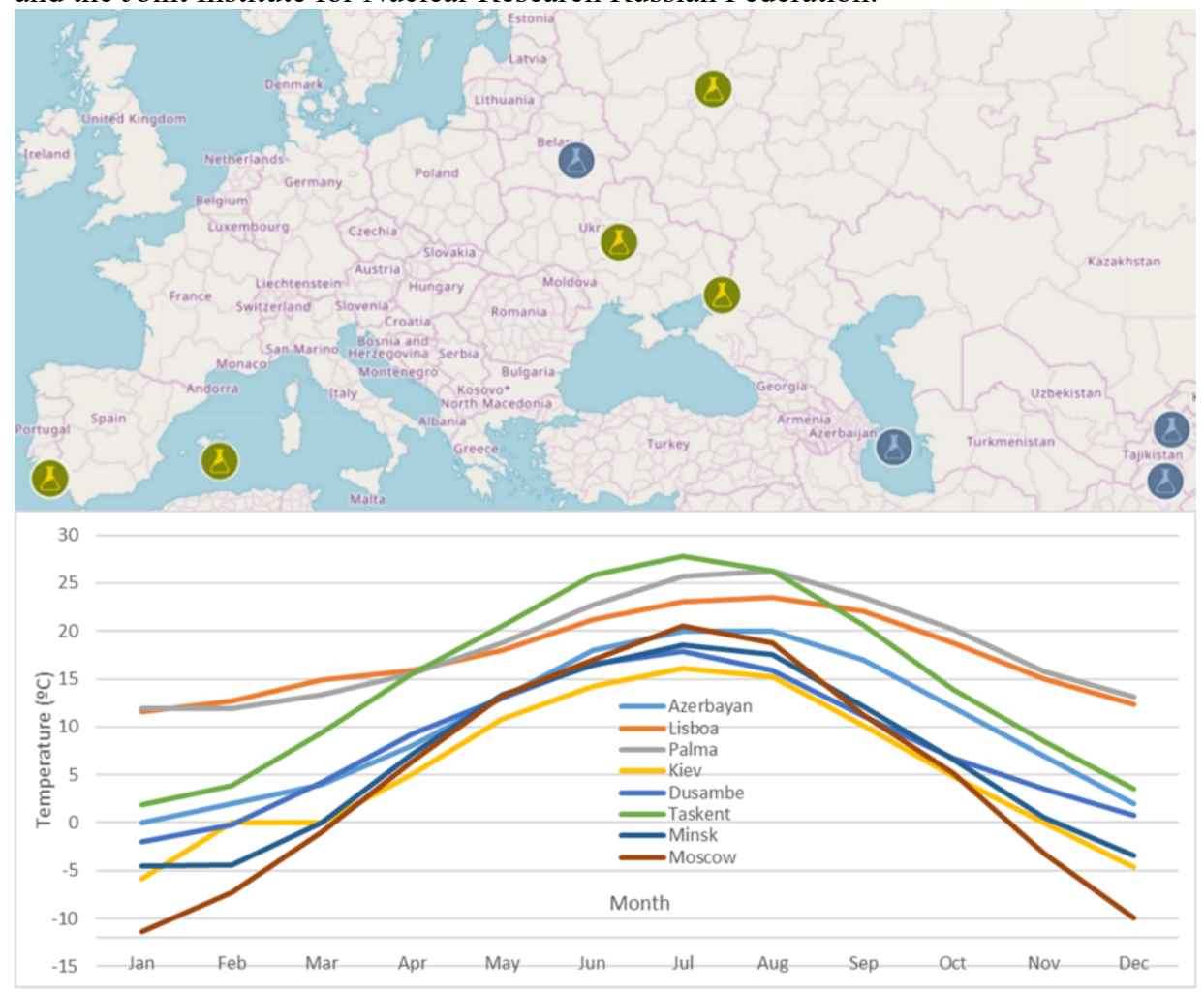

Figure 1. Average temperatures in the Cities of SSHARE project. 
The water is used for storage of energy during the year due to the high specific heat. At summer, during the hottest days $\left(28-45^{\circ} \mathrm{C}\right)$, the temperature of the storage water according to the location is between $4-18^{\circ} \mathrm{C}$, similar to the annual average temperature, see at table 1. With these low temperatures it could be used to refrigerate the building. Calcium Silicate radiant panels have been tested in a seminar room in the Balearic Islands University with success during 4 years [2] using a closed circuit. The properties of the absorption materials could be used to design open systems for radiant surfaces. The only energy consumption present to this system is a periodical electric pumping of this water from the basement to the ceilings. At the new system of recovering energy from humidity, the maximum power density produced by investigated tablets was estimated around 10 $\mathrm{nW} / \mathrm{cm}^{2}[5]$ but by increasing the density of the $\mathrm{ZrO}_{2}$ this could arrive up to $1 \mathrm{~W} / \mathrm{m}^{2}$. In Europe, it has been estimated that around 1.4 million $\mathrm{GWh} /$ year can be saved and 400 million tons of $\mathrm{CO}_{2}$ emissions avoided, in buildings and in industrial sectors by more extensive use of heat and cold storage [6].

Table 1. Climate conditions of the members of the SSHARE project

\begin{tabular}{rrrrr}
\hline Country & City & $\begin{array}{c}\text { Average } \\
\text { Temperature }\left({ }^{\circ} \mathbf{C}\right)\end{array}$ & $\begin{array}{c}\text { Precipitation } \\
\left(\mathbf{1} / \mathbf{m}^{\mathbf{2}} \text { year) }\right.\end{array}$ & $\begin{array}{c}\text { Maximum } \\
\text { Temperature } \\
\left(\mathbf{}^{\mathbf{C}} \mathbf{)}\right)\end{array}$ \\
\hline Spain & Palma & 18.2 & 449 & 38.0 \\
Portugal & Lisboa & 17.5 & 774 & 44.0 \\
\hline Azerbayan & Baku & 4 & 1252 & 28.0 \\
Ukraine & Kiev & 4.9 & 619 & 39.4 \\
Tajikistan & Dusambe & 8.2 & 568 & 45.0 \\
Uzbekistan & Taskent & 14.8 & 427 & 44.6 \\
Belarus & Minsk & 6.7 & 690 & 35.8 \\
Russia & Moscow & 5.8 & 707 & 38.2 \\
\hline
\end{tabular}

\section{Experimental results in a Façade.}

Tests with calcium silicate panels in combination with a water system will be carried out during the next months at the exterior on the Façade of a building. Other materials will be studied according to the location of the project and their typical constructions, in order to evaluate the evaporation rate of each permeable material.

Table 2. List of selected solid-liquid materials for sensible heat storage

\begin{tabular}{rrrrr}
\hline \multicolumn{1}{l}{ Material } & $\begin{array}{c}\text { Temperature } \\
\text { Range }\left({ }^{\circ} \mathbf{C}\right)\end{array}$ & Density $\left(\mathbf{k g} / \mathbf{m}^{\mathbf{3}}\right)$ & $\begin{array}{c}\text { Specific Heat } \\
(\mathbf{J} /(\mathbf{k g} \cdot \mathbf{K}))\end{array}$ & $\begin{array}{c}\text { Latent Enthalpy } \\
(\mathbf{k J} / \mathbf{k g})\end{array}$ \\
\hline Ice & $-10-0^{\circ} \mathrm{C}$ & 920 & 2050 & 333 \\
\hline Water & $0-100^{\circ} \mathrm{C}$ & 1000 & 4190 & 2260 \\
\hline Sand & $0-50^{\circ} \mathrm{C}$ & 1555 & 800 & \\
Rock & $0-50^{\circ} \mathrm{C}$ & 2560 & 879 & \\
Brick & $0-50^{\circ} \mathrm{C}$ & 1600 & 840 & \\
Concrete & $0-50^{\circ} \mathrm{C}$ & 2240 & 880 & \\
Wood & $0-50^{\circ} \mathrm{C}$ & 740 & 800 & \\
Mineral wool & $0-50^{\circ} \mathrm{C}$ & 40 & 1003 & \\
Calcium Silicate & $0-50^{\circ} \mathrm{C}$ & 300 & 1000 & \\
Silica bricks & $0-50^{\circ} \mathrm{C}$ & 1820 &
\end{tabular}

An experimental building (see figure 2) made of wood situated in the Balearic Islands has been adapted in order to test the advantages of the project, and indeed different construction materials would be tested at the exterior walls simultaneously. The dimensions of the building are $2.82 \times 1.92 \times 2.65$. With a total surface of $36 \mathrm{~m}^{2}$. The initial 
studied façade will be the south with a total surface of $7,5 \mathrm{~m}^{2}$. There is a Heat Pump combined with PV panels. In order to maintain the temperature and test all the conditions, different sensors have been installed inside and outside.

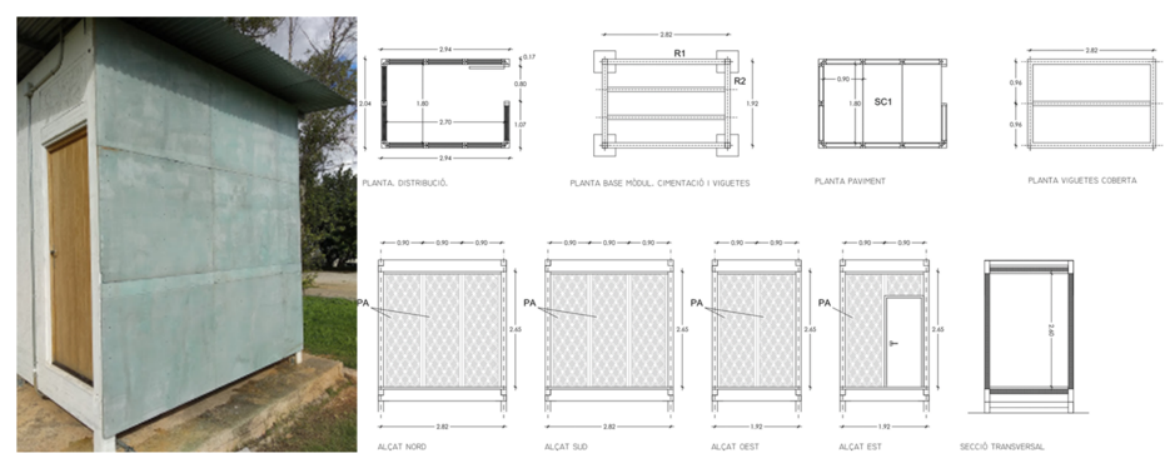

Figure 2. Experimental building.

$$
\dot{Q}_{\text {wall }}=\left[(\tau \alpha)_{0} F_{R} G_{T}-U_{L}\left(T_{\text {wall }}-T_{\text {amb }}\right)\right] S_{a}
$$

The walls are gaining energy due to the solar radiation according to the material, mass, absorptivity and weather conditions (temperature of the air, solar radiation wind,..). In Palma de Majorca a light façade $\left(100 \mathrm{~kg} / \mathrm{m}^{2}\right)$ could exceed the $50^{\circ} \mathrm{C}$, when the environmental temperature is almost $30^{\circ} \mathrm{C}$.

Irrigating the wall during the hours of maximum solar radiation at summer can reduce the temperature of the wall by the consumption of water. This results into two effects: a sensible energy from the low enthalpy of the water to the permeable material of the external side of the wall and a second one with the latent heat of the evaporative effect. The flow of the water ( $\mathrm{kg} /$ hour) and the evaporation $(\mathrm{kg} /$ hour) will be tested so as to gain a better understanding of the thermal behavior of permeable walls under dry and wet conditions. It has been proven by other studies that the evaporation will be higher according to the Humidity, wind and solar radiation. The relative humidity and wind velocity have a linear rank correlation with the evaporation [9].

$$
\begin{aligned}
& Q_{\text {transmision }}=U_{L} \cdot S \cdot\left(T_{\text {wall }}-T_{\text {in }}\right)-Q_{\text {water }} \\
& Q_{\text {water }}=\text { Flow } \bullet 4,19\left(T_{\text {wall }}-T_{\text {water }}\right)+\operatorname{Evaporation}(2,29)
\end{aligned}
$$

At the moment the tests carried are the following; Test 1: The preliminary simulated results and some real tests demonstrate us that the heat transmission could be reduced to a $20 \%$, using less than $0,8 \mathrm{kgH}_{2} \mathrm{O} / \mathrm{m}^{2}$ day. Test 2 : With more water and a porous material the transmission could be reduced an $80 \%$, using less than $2,3 \mathrm{kgH}_{2} \mathrm{O} / \mathrm{m}^{2}$ day, the external side of the wall can arrive to the wet-bulb temperature (WBT), according to the Humidity conditions and porosity of the material. 


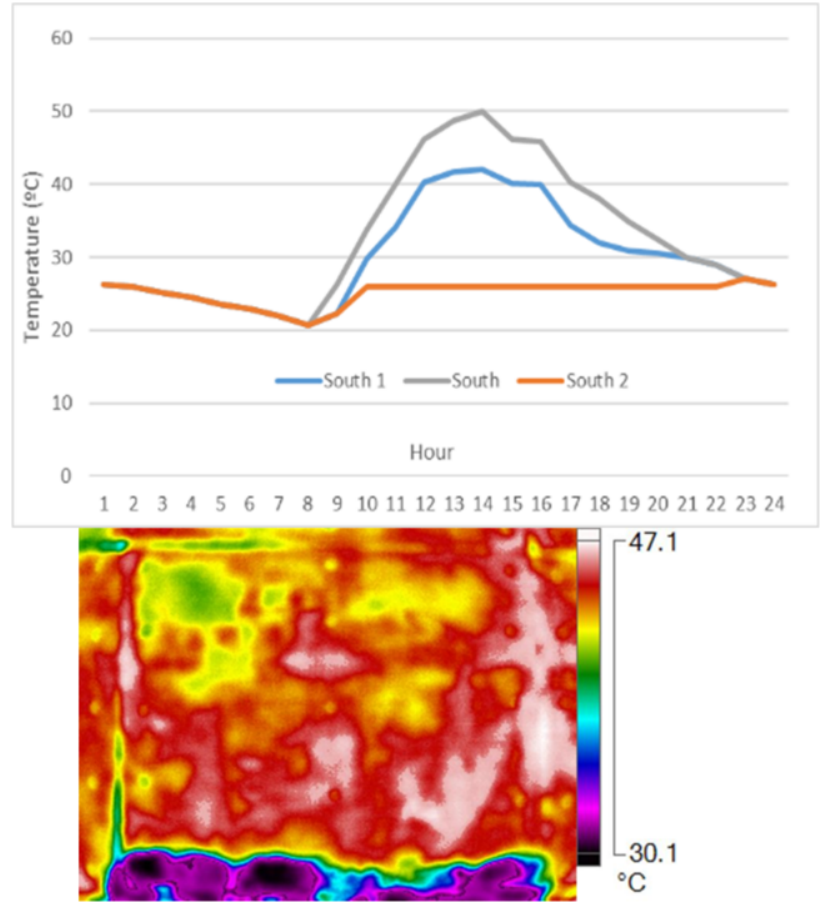

Figure 3. Temperatures of the south-east façade with different scenarios and first test.

With the preliminary results, the maximum amount of electricity for pumping with the new SSHARE System would be $1 \mathrm{~W} / \mathrm{m}^{2} * 7,5 \mathrm{~m}^{2}$ which means $7 \mathrm{~W}$.

At normal summer weather days, this power can provide a water flow of $36 \mathrm{~kg} / \mathrm{h}$, in the initial testing, only was needed a maximum water flow of $0,7 \mathrm{~kg} / \mathrm{h} \mathrm{m}^{2}$ to reduce the temperature of the external wall. At extreme summer days a maximum of $0,23 \mathrm{~m}^{3}$ could be used. As the precipitation in Majorca is very low - near $4491 / \mathrm{m}^{2}$ per year - for the studied building the water storage necessary could be about $2,43 \mathrm{~m}^{3}$. This amount is enough to reduce the consumption with the proposed system, and destine the rest for other purposes. 


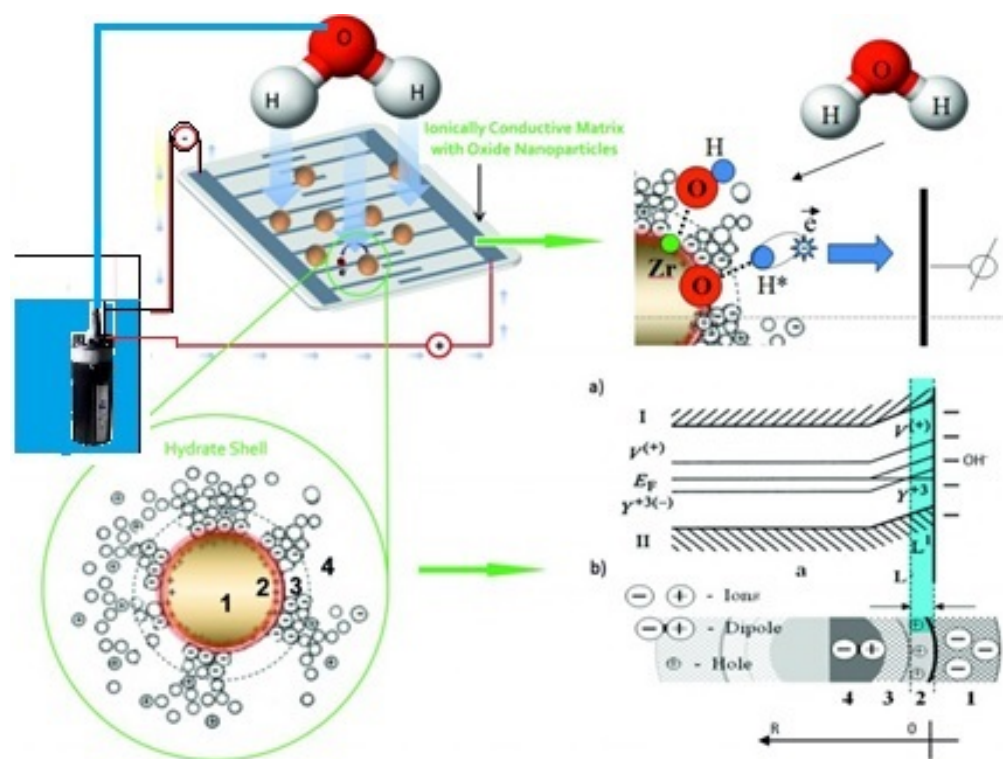

Figure 4. Schematic representation of ionic atmosphere surrounding a $\mathrm{ZrO}_{2}$ nanoparticle [8]

\section{Conclusions}

The SSHARE project is expecting to arrive to zero energy buildings using water to reduce the energy consumption of the HVAC and recovering the produced energy. The water has to be considered as a renewable energy source, with the preliminary results, the recollected water is more than used water which makes it a sustainable system.

\section{Acknowledgments}

This work was supported by the grant SSHARE Grant agreement ID: 871284 from MSCA-RISE-2019 - Research and Innovation Staff Exchange

\section{References}

[1] A Comprehensive Review of Thermal Energy Storage. Ioan Sarbu and Calin Sebarchievici. Sustainability. MDPI, Basel, Switzerland 14 January 2018.

[2] Solar Seminar Room in the University of Balearic Islands with a New Advanced Radiant System (DOI: 10.18086/eurosun2018.06.07). EUROSUN 2018.Rapperswil, Switzerland. September 2018

[3] Experimental investigation on the influence of evaporative cooling of permeable pavements on outdoor thermal environment. Junsong Wang, Qinglin Meng, Kanghao Tan, Lei Zhang, Yu Zhang.( https://doi.org/10.1016/j.buildenv.2018.05.033) Building and Environment. Elsevier May. 2018.

[4] Solar and heat pump systems. An analysis of several combinations in Mediterranean areas. Andreu Moià Pol, Víctor Martínez Moll, Miquel Alomar Barceló, Ramon Pujol Nadal. January 2012 Strojarstvo. 449-454, Rijeka, Croatia.

[5] Experimental evidence for chemo-electronic conversion of water adsorption on the surface of nanosized yttria-stabilized Zirconia. A. Lyubchyk, H. Águas, E. Fortunato, R. Martins, O. Lygina, S. Lyubchyk, N. 
Mohammadi, E. Lähderanta, A. S. Doroshkevich, T. Konstantinova, I. Danilenko, O. Gorban, A. Shylo, V. K. Ksenevich, and N. A. Poklonski. H2020-MSCA-RISE-2015 (http://www.worldscientific.com/doi/abs/10.1142/9789813224537_0059)

[6] International Renewable Energy Agency (IRENA). The Energy Technology Systems Analysis Programmes(ETSAP): Technology Brief E17; International Energy Agency: Paris, France, 2013. Available online:http://www.irena.org/Publications (accessed on 8 July 2015).68.

[7] Influence of a pulsed magnetic field on the electrical properties of nanopowder system based on zirconia. Artem Shylo1, Aleksandr Doroshkevich, Tetyana Konstantinova, Igor Danilenko. (DOI 10.12776/ams.v23i3.970) Acta Metallurgica Slovaca, Vol. 23, 2017, No. 3, p. 208-214

[8] http://hunter-greenenergy.com/about-us-sshare/

[9] Wind Evaporation on Wet Surfaces under uncertainty Conditions. J.M. Gozálvez-Zafrilla et.al. Universidad Politécnica de Valencia, Spain. Excerpt from the Proceedings of the COMSOL Conference 2010 Paris.

[10] Study on building integrated evaporative cooling of large glass-covered spaces. Dereck.Vissers. Department Building Physics and Systems at Eindhoven .University of Technology. Eindhoven. NL 2011 